\title{
Composite Particles Formation and Behaviour in Al-Li Alloys Alloyed by Sc (Zr) under Heat Treatment and Severe Plastic Deformation
}

\author{
O.A. MoleBnyI ${ }^{a, *}$, A.L. BerezinA ${ }^{a}$ AND A.V. KotKo ${ }^{b}$ \\ ${ }^{a}$ Institute for Metal Physics of the NAS of Ukraine, Vernadsky Blvd. 36, 03680, Kyiv, Ukraine \\ ${ }^{b}$ Institute for Problems of Materials Science of the NAS of Ukraine, Krzhizhanovskii Str. 3, 03680, Kyiv, Ukraine
}

\begin{abstract}
The mechanism and kinetics of $\mathrm{Al}_{3} \mathrm{Li} / \mathrm{Al}_{3} \mathrm{Sc}$ composite particles formation during aging of triple $\mathrm{Al}-\mathrm{Li}-\mathrm{Sc}$ alloys were studied. The particles of such type consist of two isomorphic phases, ordered by $L 1_{2}$ type. Composite particles in $\mathrm{Al}-\mathrm{Li}-\mathrm{Sc}$ are formed by epitaxial nucleation of $\delta^{\prime}\left(\mathrm{Al}_{3} \mathrm{Li}\right)$ phase on pre-existing $\mathrm{Al}_{3} \mathrm{Sc}$ precipitates at low temperature aging in the area of existence of $\mathrm{Al}_{3} \mathrm{Li}$ phase, and form uniform shell around them. The motive force of such heterostructure formation is the minimization of total surface, elastic and chemical energy of the alloy. Dark-field transmission electron microscopy images of such composite particles taken from superlattice reflex 100 are composed of a dark core surrounded by a bright shell. The mutual diffusion of Li and Sc during the aging of $\mathrm{Al}-\mathrm{Li}-\mathrm{Sc}$ alloys is observed. The dark-field transmission electron microscopy image of the composite particle obtained from superlattice reflection became transparent after continuous natural aging of $\mathrm{Al}-\mathrm{Li}-\mathrm{Sc}$ alloys. The presence of the particle in $\mathrm{Al}$ matrix can be only seen due to decoration by secondary precipitations of $\delta^{\prime}\left(\mathrm{Al}_{3} \mathrm{Li}\right)$ phase. Composition analysis of such transparent particles was carried out using two-beam kinematical theory of electron diffraction. Such composite particles with transparent cores remain in Al matrix even after severe plastic deformation of $\mathrm{Al}-\mathrm{Li}-\mathrm{Sc}$ alloy.
\end{abstract}

DOI: 10.12693 /APhysPolA.128.564

PACS: 64.70.dg, 81.07.Bc, 81.10.Fg

\section{Introduction}

Currently, the formation of new types of strengthening particles is of great interest. Such heterophase nanocomposite particles are formed during aging and consist of two parts: the core and the shell. The shells of particles have structures that could not be interpreted as conventional heterogeneous formation of a new phase on the existing surface. $\mathrm{Al}_{3} \mathrm{Sc}$ particles are known to be the preferred location for the nucleation of phases that are not isomorphic to the matrix, especially for additives with low solid solubility. Needle-phase precipitation of $\mathrm{Fe}$ compound on $\mathrm{Al}_{3} \mathrm{Sc}$ particle is shown in Fig. 1a. In this

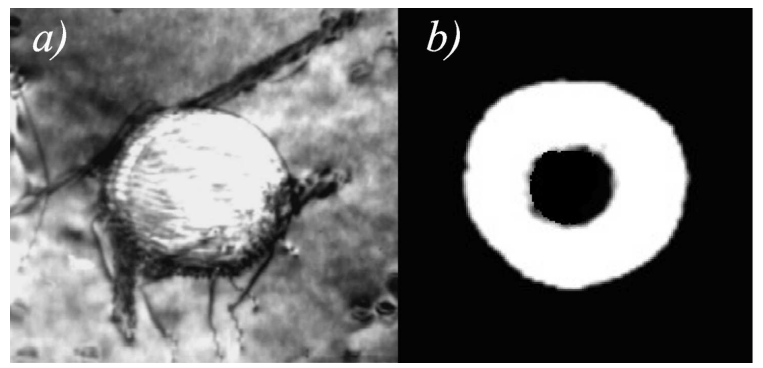

Fig. 1. Morphology of precipitates on Al3Sc particle: (a) heterogeneous Fe-containing needle-phase precipitate (bright field), (b) Al3Li-phase shell formation and nanocomposite Al3Li/Al3Sc particle generation (dark field in the superlattice reflection of $L 1_{2}$ phase).

* corresponding author; e-mail: moleb@imp.kiev.ua case the surface energy changes locally in the place where different phases are in contact. In $\mathrm{Al}-\mathrm{Li}-\mathrm{Sc}$ alloys the metastable $\delta^{\prime}$-phase $\left(\mathrm{Al}_{3} \mathrm{Li}\right)$ produces a shell on $\mathrm{Al}_{3} \mathrm{Sc}$ particles during aging (see Fig. 1b). This shell changes the value of the interface energy and elastic stress produced by strengthening particles in the matrix. The decomposition and properties of ternary $\mathrm{Al}-\mathrm{Sc}-\mathrm{X}$ alloys (where $\mathrm{X}-\mathrm{Zr}, \mathrm{Hf}, \mathrm{Ti}$ and rare earth metals) and $\mathrm{Al}-$ $\mathrm{Zr}-\mathrm{Ti}$ alloys, which are characterized by nanocomposite particles formation, were investigated giving the evidence about the increase of strength, fatigue properties and creep resistance [1-6].

The mechanism and kinetics of $\mathrm{Al}_{3} \mathrm{Li} / \mathrm{Al}_{3} \mathrm{Sc}$ two-phase composite nanoparticles formation in the process of aging of ternary $\mathrm{Al}-(2-3) \% \mathrm{Li}-(0.1-0.6) \% \mathrm{Sc}$ alloys were studied $[2,3]$. The particles of this type consist of two isomorphic phases with $L 1_{2}$ type order. Constituents of $\mathrm{Al}_{3} \mathrm{Sc}$ and $\mathrm{Al}_{3} \mathrm{Li}$ phases precipitate at different aging temperatures.

Spherical high-strength coherent particles of $\mathrm{Al}_{3} \mathrm{Sc}$ phase appear during crystallization, homogenization and high-temperature technological annealing. Composite particles $\mathrm{Al}-\mathrm{Li}-\mathrm{Sc}$ are formed by epitaxial nucleation of $\delta^{\prime}$ $\left(\mathrm{Al}_{3} \mathrm{Li}\right)$ phase on pre-existing $\mathrm{Al}_{3} \mathrm{Sc}$ precipitates during further low-temperature aging in the range of $\mathrm{Al}_{3} \mathrm{Li}$ phase existence, and produce uniform shells around them.

The cause of composite nanoparticle formation are the processes of solid phase heteroepitaxy during which the interface of $\mathrm{Al}_{3} \mathrm{Sc}$ particles is enriched with $\mathrm{Li}$, followed by nucleation of particles of the new $\mathrm{Al}_{3} \mathrm{Li}$ phase. In the process of their coalescence, a continuous single-crystal epitaxial film is formed (due to full 
structural-geometrical match of phases forming the composite particle). The driving force of such heterostructure formation is the minimization of the total surface, elastic and chemical energy of the alloy. Formation kinetics is given by the degree of solid solution supersaturation and aging temperature.

The subject of this study is to examine and identify structural changes in nanocomposite particles caused by complex multistage aging modes: artificial aging + natural long-term aging (for more than 25 years) + dynamic aging of $\mathrm{Al}-\mathrm{Li}-\mathrm{Sc}$ alloys at temperatures ranging from 20 to $460^{\circ} \mathrm{C}$.

\section{Experimental}

The investigation was carried out using the electricalresistivity, metallography and electron microscopy methods.

$\mathrm{Al}-3 \mathrm{Li}-0.3 \mathrm{Sc}$ alloy (alloy 1 ) and $\mathrm{Al}-3 \mathrm{Li}-0.7 \mathrm{Sc}$ alloy (alloy 2) were studied. Alloys were homogenized at $580^{\circ} \mathrm{C}$, quenched and aged at $175^{\circ} \mathrm{C}$ for $16 \mathrm{~h} \mathrm{[2]}$.

Besides, the structure and properties of $\mathrm{Al}-2.3 \% \mathrm{Li}-$ $3 \% \mathrm{Cu}-0.1 \% \mathrm{Sc}-0.1 \% \mathrm{Zr}$ (commercial 1460 alloy) were studied after friction-stir welding (FSW) of thin coldrolled sheets $2 \mathrm{~mm}$ thick. Before FSW, sheets were aged in the T8 mode and then continuously naturally aged at room temperature. During FSW, severe plastic deformation and material flow occurs at temperatures lower than melting temperature. Welding was performed at the tool rotation speed of $2880 \mathrm{rps}$. The tool moves along the weld joint at constant speed of $16 \mathrm{~m} / \mathrm{h}$.

Metallographic studies were carried out on polished and etched cross-section. Etching was done using the Keller reagent at room temperature. Four different etching zones were observed: A - stirred zone (SZ) B and C - thermo-mechanically affected zone (TMAZ), D heat affected zone (HAZ), E - base metal (BM). The location of HAZ can be recognized from hardness measurements (Fig. 2).

The half-plate where the direction of tool rotation is the same as the direction of half-plate motion is called the retreating side (marked as $\mathrm{C}$ ), with the other side designated as the advancing side (marked as B). Extrusion phenomena were observed on the retreating side. This gives the proof that material flows from the advancing to the retreating side during FSW [7].

The phase composition as well as dislocations and grain sizes were observed in the base material and FSW sample using transmission electronic microscopy (TEM). Disc specimens (3 $\mathrm{mm}$ in diameter) were prepared by mechanical grinding to $250 \mu \mathrm{m}$ thickness and electropolishing using a $30 \%$ nitric acid solution in methanol with $60 \mathrm{~V} \times 1 \mathrm{~A}$ at $20^{\circ} \mathrm{C}$. Material for these specimens was taken from different weld zones at four different sites along the midthickness of the cross-section of the FSW sample (marked by rectangles in Fig. 2).

Resistance measurements were performed using a fourprobe dc method. The temperature coefficient of electrical resistivity $\alpha_{\mathrm{T}}=1 / R_{0} \times \mathrm{d} R / \mathrm{d} T$ was monitored during

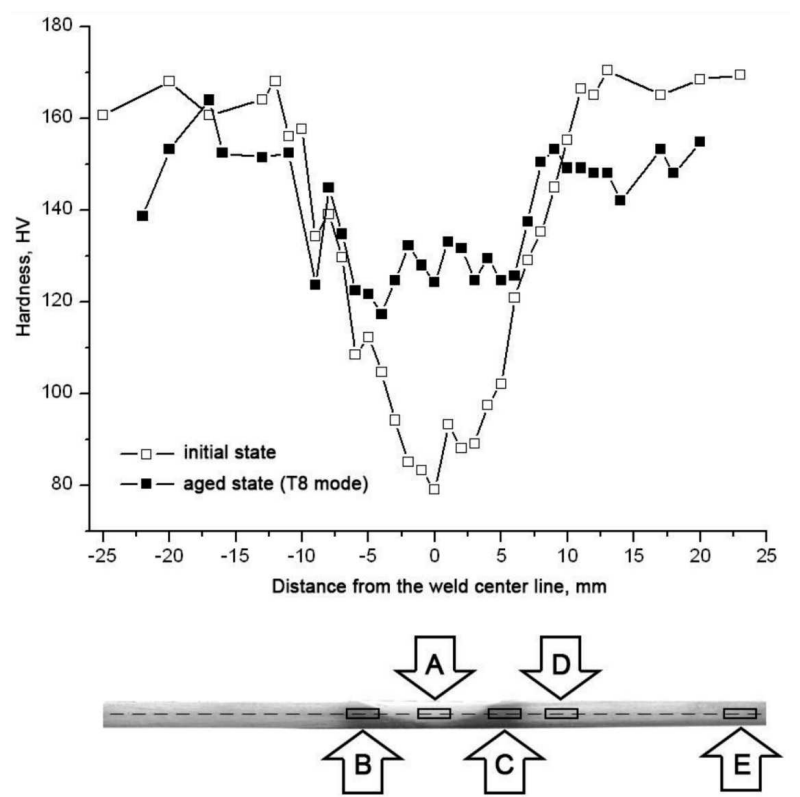

Fig. 2. The Vickers hardness plot scaled to the weld macrostructure picture. Four different zones were observed: A - stirred zone (SZ), B and C - thermomechanically affected zone (TMAZ), D - heat affected zone (HAZ), E - base metal (BM).

continuous heating at the heating rate of $3{ }^{\circ} \mathrm{C} / \mathrm{min}$ in the temperature range from room temperature up to $600{ }^{\circ} \mathrm{C}$.

\section{Results and discussion}

\subsection{Structure of nanocomposite particles after long-term natural aging}

Curves $\alpha_{\mathrm{T}}=f(T)$ show that the supersaturated solid solution after quenching decomposes in the lowtemperature minimum range by the precipitation of a metastable phase (Fig. 3a). In this temperature range 130-200 nm nanocomposite $\mathrm{Al}_{3} \mathrm{Li} / \mathrm{Al}_{3} \mathrm{Sc}$ particles are formed and they have characteristic TEM dark field contrast with decreasing intensity in the center of the particle (see Fig. 1b, 3c). The precipitated $\delta^{\prime}$-phase particles have homogeneous dark field contrast and theirs size is significantly smaller $(5-15 \mathrm{~nm})$ than the size of composite particles (Fig. 3c).

The low-temperature minimum disappears on the $\alpha_{\mathrm{T}}=f(T)$ curves after long-term natural aging. A diffuse maximum replaces the low-temperature minimum (see Fig. 3b). The matrix is fully depleted from Li atoms and Ostwald ripening occurs at higher temperature; it is accompanied with the growth of metastable $\delta^{\prime}$-phase particles and the decrease of their density in the matrix about $300{ }^{\circ} \mathrm{C}$ a stable $\delta(\mathrm{AlLi})$ is formed.

The temperature coefficient of electrical resistivity of the commercial 1460 alloy is shown in Fig. 4. Two temperature regions are present in all curves (Fig. 4). There is a positive peak in the low-temperature region indicating $\delta^{\prime}$-phase dissolution and there is the negative peak in the high-temperature region related to $T_{1}$-phase and 


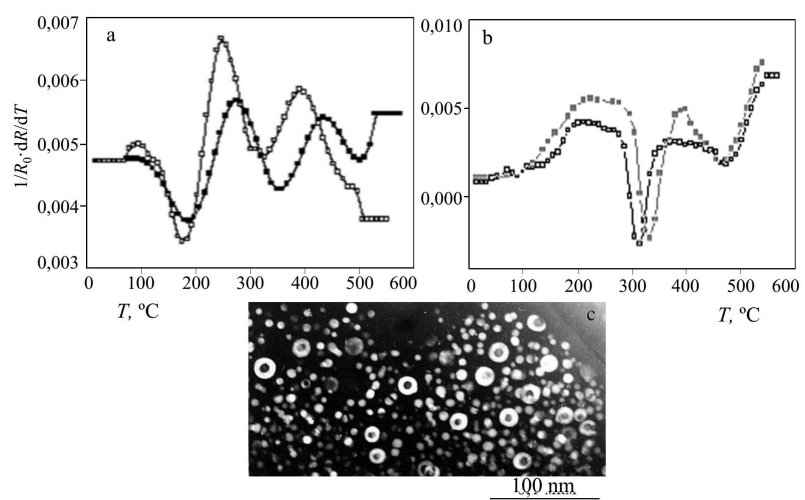

Fig. 3. Changes in the temperature coefficient of electrical resistivity $\alpha_{\mathrm{T}}=\left(1 / R_{0} \times \mathrm{d} R / \mathrm{d} T\right)$ of alloys $1(\boldsymbol{\square})$ and $2(\square)$ during continuous heating at the rate of $3{ }^{\circ} \mathrm{C} / \mathrm{min}$ after quenching from $580^{\circ} \mathrm{C}(\mathrm{a}), 175^{\circ} \mathrm{C} \times 16 \mathrm{~h}$ + natural aging for about 25 years at room temperature (b), structural state of alloy Al-2\%Li-0.3\% Sc after artificial aging $175^{\circ} \mathrm{C} \times 16 \mathrm{~h}(\mathrm{c})$.

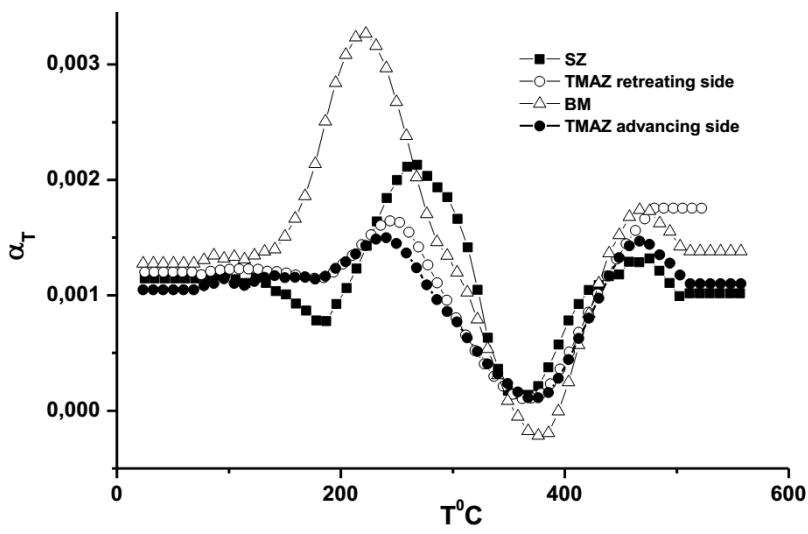

Fig. 4. Changes in the temperature coefficient of electrical resistivity $\alpha_{\mathrm{T}}$ of the commercial 1460 alloy during continuous heating at the rate $3{ }^{\circ} \mathrm{C} / \mathrm{min}$ in $20-600^{\circ} \mathrm{C}$ temperature range.

stable $\delta$-phase formation. A small negative peak on the "SZ" curve (welded joint zone) in Fig. 4 located before the $\delta^{\prime}$-phase dissolution peak shows that the material of the joint core has been partially transformed into solid solution under intensive plastic deformation during FSW. There is no negative peak in other curves in Fig. 4 like as in Fig. 3b. This is due to the fact that half-sheets of 1460 alloy have been naturally aged for a long time before FSW (as alloys in Fig. 3b).

TEM studies have shown that long-term natural aging has completely changed the dark field contrast of composite particles (see Fig. 3c, 5b).

$\mathrm{Al}_{3}$ Sc particles of $130-200 \mathrm{~nm}$ size have different type of interface with matrix, i.e. coherent, incoherent and semicoherent (Fig. 5a) and the characteristic dark field contrast with a small intensity in the center of the particle disappears (Fig. 5b) and the composite particle core becomes "transparent".

The composite $\mathrm{Al}_{3} \mathrm{Li} / \mathrm{Al}_{3} \mathrm{Sc}$ nanoparticles with characteristic dark field (DF) contrast of $\mathrm{Al}_{3} \mathrm{Sc}$ core were

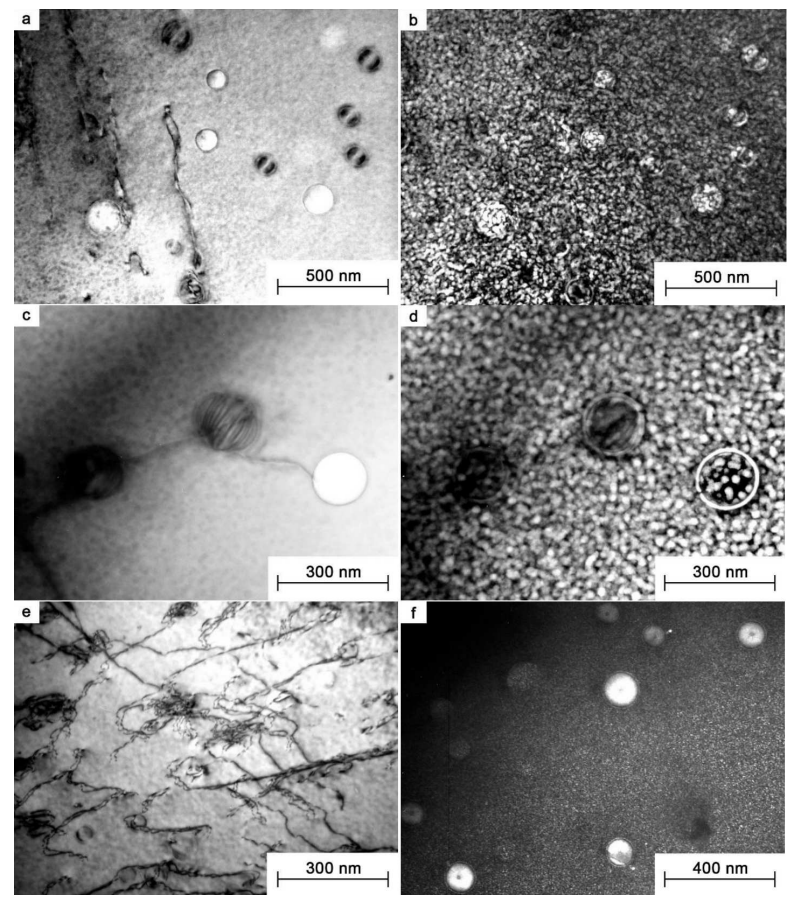

Fig. 5. The structure of Al-3Li-0.3Sc alloy after longterm natural ageing of pre-aged specimens $(a, b)$, natural aging + continuous heating to $230^{\circ} \mathrm{C}(\mathrm{c}, \mathrm{d}, \mathrm{e})$, natural aging + continuous heating to $460{ }^{\circ} \mathrm{C}$ (f), (a,c,e) bright field, $(b, d, f)$ dark field in the superlattice reflection (100) of $\delta$-phase.

observed after continuous natural aging for 25 years. $L 1_{2}$-ordered $\mathrm{Al}_{3} \mathrm{Sc}$ core gives zero intensity on DF TEM images in 100 superstructural reflection (Fig. 5b). This proves that the nanoparticle consists of $\mathrm{Al}_{3} \mathrm{Sc}_{x} \mathrm{Li}_{1-x}$ core and the shell of $\mathrm{Al}_{3} \mathrm{Li}$ with $\mathrm{L1}_{2}$ order in the disordered matrix. Modelling of theoretical electron images (TEI) of such composite nano-particles has been made $[8,9]$. The calculation of the intensity of scattered electrons was done within the kinematic approach of the electron scattering theory. Scattering in the direction of superlattice reflections occurs only in the ordered particle and does not occur in the disordered matrix. The amplitude of electron scattering in the kinematic approach is as follows:

$$
\Phi(x, y)=\frac{\mathrm{i} \lambda}{V_{c} \cos \Theta} \int F_{\mathrm{g}} \exp (-2 \mathrm{i} \pi s z) \mathrm{d} z,
$$

where $F_{\mathrm{g}}$ is the structural factor equal to $F_{\text {core }}$ value in the core of the composite particle, $F_{\text {shell }}$ - in the shell and $0-$ in the matrix. Integration is carried out through the thickness of the composite particle within the column approximation [10].

"Transparency" of the composite particle core observed in the dark field images in superlattice reflection implies zero structural factor. If Li solubility in the core is taken into account $[11,12]$, the core structure factor with variable composition $\mathrm{Al}_{3} \mathrm{Li}_{x} \mathrm{Sc}_{1-x}$ is described as

$$
F_{h k l}=x f_{\mathrm{Li}}+(1-x) f_{\mathrm{Sc}}-f_{\mathrm{Al}},
$$


where $F$ is the resulting structure factor; $f_{\mathrm{Li}}, f_{\mathrm{Sc}}, f_{\mathrm{Al}}$ are electron scattering factors for atoms of $\mathrm{Li}, \mathrm{Sc}$, and $\mathrm{Al}$, respectively [8].

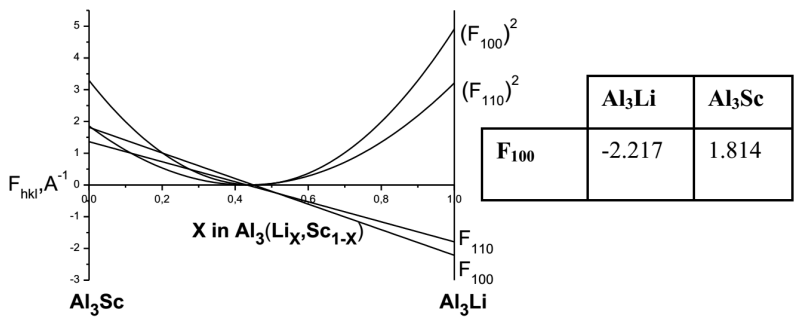

Fig. 6. Structure factors and their squares for the superlattice 100, 110 reflections as a function of core composition. Image intensity is proportional to $F^{2}$.

The structure factor $F_{100}$ changes from 1.814 for $\mathrm{Al}_{3} \mathrm{Sc}$ phase to -2.217 for $\mathrm{Al}_{3} \mathrm{Li}$ phase [9] when $x$ changes from 0 to 1 (Fig. 6). It means that the structure factor of the reflection changes its sign in the region of interphase of the composite $\mathrm{Al}_{3} \mathrm{Li} / \mathrm{Al}_{3} \mathrm{Sc}$ particle.
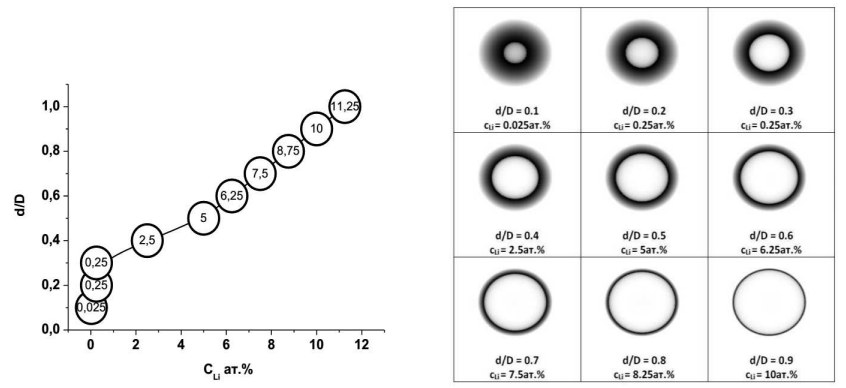

Fig. 7. The dependence of the dark field image "transparency" of the composite $\mathrm{Al}_{3} \mathrm{Li} / \mathrm{Al}_{3} \mathrm{Sc}_{x} \mathrm{Li}_{1}-x$ particle in superlattice reflection $\boldsymbol{g}=100$ on the ratio of core diameter (d) to that of the whole particle (D) $d / D$ and on $\mathrm{Li}$ concentration in the composite particle core $\mathrm{C}_{\mathrm{Li}}$.

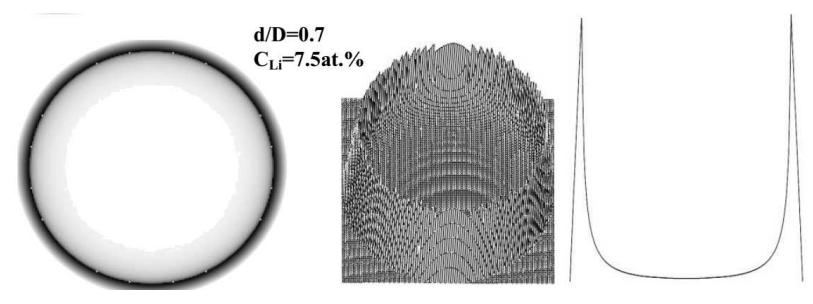

Fig. 8. Dark field contrast from the composite particle in 100 reflection: (a) TEI, (b) 3D intensity distribution; (c) intensity profile.

The dependence of the dark field image "transparency" of the composite $\mathrm{Al}_{3} \mathrm{Li} / \mathrm{Al}_{3}\left(\mathrm{Li}_{x}, \mathrm{Sc}_{1-x}\right)$ particle on $d / D$ (the ratio of the core diameter $d$ to the whole particle diameter $D$ ) in the superlattice reflection $\boldsymbol{g}=100$ was calculated by Beresina et al. (see Fig. 7 and Fig. 8) [9].
Using this dependence Li content in the core can be determined. For example, to get "transparency" for $\mathrm{Al}_{3} \mathrm{Sc}$ particle without shell $(d / D=1)$ the content of Li must be 11.35 at. $\%$.

After long-term natural aging all composite particles become transparent irrespective of the type of interface with the matrix (see Fig. 5b). The shell is absent $\left(d / D=1\right.$ and $C_{\mathrm{Li}} \approx 11.35$ at.\% Li for particles with $D>170 \mathrm{~nm}$. For particles with $D<170 \mathrm{~nm}$, $d / D$ changes in the interval of $0.75-0.9$; this corresponds to $\mathrm{Li}$ content variation in the particle core in the range of $8.5-10$ at. $\%$.

\subsection{Thermal stability of the composite particles under dynamic ageing}

To understand the thermal stability of composite particles their structures were investigated after dynamic aging during continuous heating up to the selected points in the $\alpha_{\mathrm{T}}=f(T)$ curve (see Fig. 3b): 230, 325, 395, and $460^{\circ} \mathrm{C}$ (correspond to extrema in $\alpha_{\mathrm{T}}=f(T)$ ).

After heating to $230^{\circ} \mathrm{C}$ the composite particles retain their "transparency", they have shells and $C_{\mathrm{Li}} \approx 10$ at.\%. The presence of dislocations in the $\mathrm{Al}_{3} \mathrm{Li} / \mathrm{Al}_{3} \mathrm{Sc}$ interface (semicoherent particle in Fig. 5c) changes the contrast and the discontinuous shell in the dark field images and non-transparent stripes in places where dislocations emerge on the surface of the core are observed (see Fig. 5d). The loss of coherence between $\alpha$-solid solution and $\mathrm{Al}_{3} \mathrm{Li}$ on the interphase is caused by the ejection of the dislocation into the matrix and the formation of complex dislocation structure near the particle (Fig. 5e). Screw dislocations move in the matrix bend around the composite particles but they can cut $\delta^{\prime}$-phase particles. The evidence of $\delta^{\prime}$-phase particles cutting intersection is the splitting of the whole dislocation into two partial ones $(a / 2)\langle 110\rangle$ with oscillating distance between them (see Fig. 5e) [13].

When the temperature rises from 325 to $395{ }^{\circ} \mathrm{C}$ (above the region of the existing $\delta^{\prime}$-phase) $\mathrm{Al}_{3} \mathrm{Li}$ phase dissolves, the shell disappears and the equilibrium $\delta$-phase forms. After heating of the alloy up to $460^{\circ} \mathrm{C}$ (the region of homogeneous Li solid solution in $\mathrm{Al}$ ) $\mathrm{Al}_{3} \mathrm{Sc}$ particles produce deformation contrast and a pore of $\approx 12 \mathrm{~nm}$ in size is observed in these interior (see Fig. 5f). The pore formation is due to the vacancy supersaturation of $\mathrm{Al}_{3} \mathrm{Sc}$ phase as $\mathrm{Li}$ diffuses from the particle into the matrix.

\subsection{Structural state of nanocomposite particles in $\mathrm{Al}-2.3 \% \mathrm{Li}-3 \% \mathrm{Cu}-0.1 \% \mathrm{Sc}-0.1 \% \mathrm{Zr}$ (commercial 1460 alloy) after FSW}

The respective dependence for $\mathrm{Al}_{3} \mathrm{Li} / \mathrm{Al}_{3} \mathrm{Li}_{x} \mathrm{Zr}_{1-x}$ looks similar but the amount of lithium dissolved in the particle core is higher. The maximum of dissolved $\mathrm{Li}$ corresponds to $\mathrm{Al}_{3} \mathrm{Li}_{x} \mathrm{Zr}_{1-x}$ particle without shell and is equal to $\approx 14.5 \%$.

Low-temperature heat treatment of the alloy results in a very low $\mathrm{Zr}$ content in the composite particle cores 
due to the fact that $\mathrm{Zr}$ diffusion coefficient is by an order of magnitude lower than that of Sc and therefore $\mathrm{Zr}$ generally segregates at the core/shell interface [14, 15]. Therefore, the curve shown in Fig. 7 can be also used for the estimation of $\mathrm{Li}$ content in the composite particle cores.

The maximum of lithium content in $\delta^{\prime} / \mathrm{Al}_{3}(\mathrm{Sc}, \mathrm{Zr})$ composite particles is $\approx 8-10$ at.\%. Most probably, Li content in the composite particle core remains constant after friction stir welding in spite of significant temperature increase (up to $\approx 450{ }^{\circ} \mathrm{C}$ ) in the welded joint zone during welding, because $\delta^{\prime} / \mathrm{Al}_{3}(\mathrm{Sc}, \mathrm{Zr})$ composite particles with "transparent" cores are observed in the stirred zone as well (Fig. 9a).

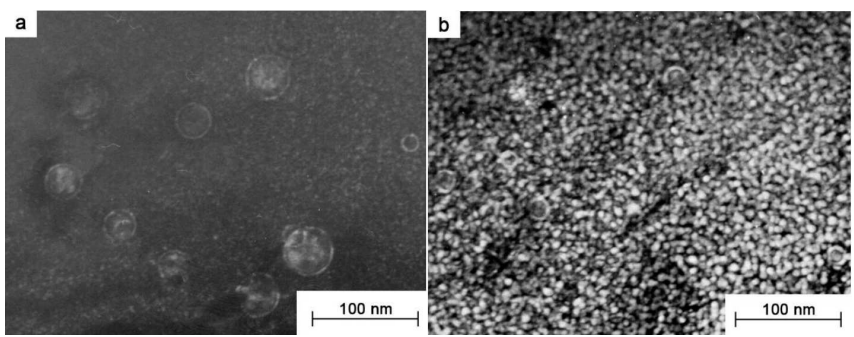

Fig. 9. Dark field image of composite $\mathrm{Al}_{3} \mathrm{Li} / \mathrm{Al}_{3} \mathrm{Li}_{x} \mathrm{Sc}_{1-x}$ particles in superlattice reflection $\boldsymbol{g}=100$ : (a) in the joint core after friction stir welding; (b) in the joint core after artificial aging in $\mathrm{T} 8$ mode $\left(160^{\circ} \mathrm{C} \times 10 \mathrm{~h}+120^{\circ} \mathrm{C} \times 20 \mathrm{~h}\right)$.

After treatment in $\mathrm{T} 8$ mode $\left(160^{\circ} \mathrm{C} \times 10 \mathrm{~h}+120^{\circ} \mathrm{C} \times\right.$ $20 \mathrm{~h}$ ) of the welded joint core, composite particles do not lose their "transparency" so Li content in their cores should correspond to values in Fig. 7 .

The increase of annealing temperature up to $350^{\circ} \mathrm{C}$ (above the region of $\delta^{\prime}$-phase existence) leads to the shell disappearance and the equilibrium $\delta$-phase formation. The following $\mathrm{Al}_{3}(\mathrm{Sc}, \mathrm{Zr})$ particle evolution differs depending on the welded position inside the zone. Pores of $\approx 10 \mathrm{~nm}$ size are observed (see Fig. 10) in centers of particles located in zone B (Fig. 2) after artificial aging of $350^{\circ} \mathrm{C}$ for $24 \mathrm{~h}$.

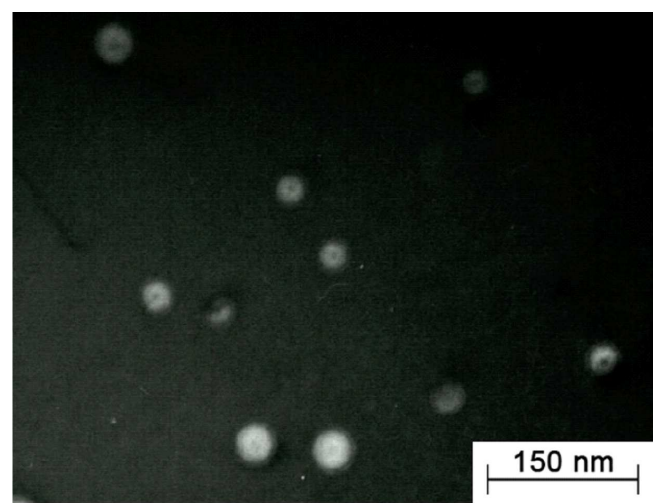

Fig. 10. Dark field image of $\mathrm{Al}_{3} \mathrm{Li}_{x} \mathrm{Sc}_{1-x}$ particles in superlattice reflection $\boldsymbol{g}=100$ after artificial aging $350^{\circ} \mathrm{C} \times 24 \mathrm{~h}$ (advancing side B).

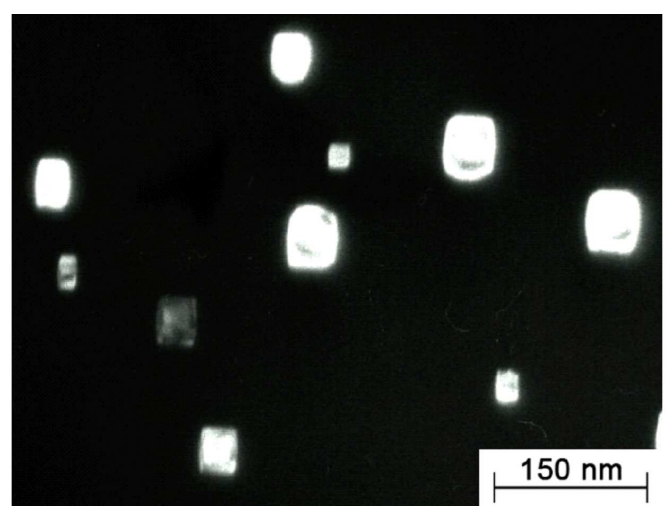

Fig. 11. Dark field image of $\mathrm{Al}_{3} \mathrm{Li}_{x} \mathrm{Sc}_{1-x}$ particles in superlattice reflection $\boldsymbol{g}=100$ after artificial aging $350^{\circ} \mathrm{C} \times 24 \mathrm{~h}$ (retreating side $\mathrm{C}$ ).

The pore in the $\mathrm{Al}_{3}(\mathrm{Sc}, \mathrm{Zr})$ particle is generated due to the Frenkel effect, when the stream of vacancies from the matrix and their accumulation in the center of the particle compensates the diffuse flow of lithium from the particle to matrix [16]. The particles of $\mathrm{Al}_{3}(\mathrm{Sc}, \mathrm{Zr})$ phase located in the zone $\mathrm{C}$ (Fig. 11) also lose lithium and become "non-transparent" after artificial aging $350{ }^{\circ} \mathrm{C}$ for $24 \mathrm{~h}$. But inside they do not contain pores. Moreover, they transform into cubes.

During friction stir welding not only material mass transfer occurs from the advancing side to the retreating side of the joint. There is also compression present in the thermo-mechanically affected zone of the retreating side of the joint, which induces material extrusion. This compression is sufficient to suppress the Frenkel sinks of vacancies, so the pore neither nucleates nor grows (the compression of about $5-10 \mathrm{MPa}$ is sufficient) [17].

The particle shape changes from spherical to cubic because of an excessive compressive stress in this region of the joint [18]. The energy of coherent deformation in the particle decreases by more than $30 \%$ after such particle shape change [19].

\section{Conclusions}

1. The shells from $\mathrm{Al}_{3} \mathrm{Li}$-phase form in the region of the existing metastable $\delta^{\prime}$-phase on all $\mathrm{Al}_{3} \mathrm{Sc}$ particles regardless of the type of interface with the matrix.

2. After long-term natural aging the dark field contrast in the superlattice reflection of the composite particle changes: beginning with the intensity extinction in the composite particle core (before natural aging) and ending with "transparency" formation after natural aging. The effect of "transparency" is explained by modelling the TEM contrast. This method is used for the determination of Li concentration in the "transparent" particle core. The lithium enrichment of $\mathrm{Al}_{3} \mathrm{Sc}$ phase is shown to be $8-11$ at.\% Li during natural aging. 
3. Dislocations do not intersect composite particles. Their precipitation with sufficient density can prevent the localization of deformation in $\mathrm{Al}-\mathrm{Li}$ alloys.

4. The $\mathrm{Al}_{3} \mathrm{Li}$ shell on the $\mathrm{Al}_{3} \mathrm{Sc}$ particle reduces elastic distortions at the interface with the matrix and therefore the critical size of $\mathrm{Al}_{3} \mathrm{Sc}$ particles is twice as large as the size of particles without shells.

5. $\mathrm{Al}_{3} \mathrm{Sc}$-phase is depleted of $\mathrm{Li}$ and is saturated by vacancies at temperatures which are above the solvus of $\delta^{\prime}$-phase.

6. The increase of temperature up to $350{ }^{\circ} \mathrm{C}$ (above the region of $\delta^{\prime}$-phase existence) leads to the shell disappearance and the formation of equilibrium $\delta$ phase. The following $\mathrm{Al}_{3}(\mathrm{Sc}, \mathrm{Zr})$ particle evolution differs, depending on the position of particles in the welded joint zone. Pores of $\approx 10 \mathrm{~nm}$ size are observed in centers of particles located in advancing side $\mathrm{B}$. The pore in the particle of $\mathrm{Al}_{3}(\mathrm{Sc}, \mathrm{Zr})$-phase is generated owing to the Frenkel effect, when the stream of vacancies from the matrix and their accumulation in the particle center compensates the diffuse Li flow from the particle to matrix. Particles of $\mathrm{Al}_{3}(\mathrm{Sc}, \mathrm{Zr})$ phase located in retreating side C also lose lithium and become "non-transparent" after artificial aging. But they do not contain vacancy pores inside. Moreover, they transform into cubes due to excessive compressive stress in this region of the joint.

\section{References}

[1] V.I. Elagin, V.V. Zaharov, S.G. Pavlenko, T.D. Rostova, Phys. Met. Metall. 60, 88 (1985).

[2] A.L. Berezina, V.A. Volkov, B.P. Domashnikov, L.N. Trophimova, K.V. Chuistov, Metallofiz. Noveishie Tekhnol. 8, 116 (1986).
[3] A.L. Berezina, V.A. Volkov, N.I. Kolobnev, I.V. Bakonina, K.V. Chuistov, in: Questions of Aviation Science and Technique. Ser. Aviation Materials, VIAMM, Moscow 1988, p. 12 (in Russian).

[4] Y. Harada, D.C. Dunand, Acta Mater. 48, 3477 (2000).

[5] Y. Harada, D.C. Dunand, Mater. Sci. Eng. A 686, 329 (2002).

[6] K.E. Knipling, D.C. Dunand, D.N. Seidmen, Acta Mater. 56, 114 (2008).

[7] R. Nandan, T. DebRoy, H.K.D.H. Bhadeshia, Prog. Mater Sci. 53, 980 (2008).

[8] F.W. Gale, B. Vandersande, Acta Metall. 37, 1033 (1989).

[9] A.L. Berezina, O.A. Molebnyi, T.A. Monastyrskaja, Nanosist. Nanomater. Nanotekhnol. 4, 803 (2006).

[10] P. Hirsch, A. Howie, R.B. Nicholson, D.W. Pashley, M.J. Whelan, Electron Microscopy of Thin Crystals, R.E. Krieger Publishing, Malabar, FL 1977.

[11] M.E. Krug, D.C. Dunand, D.N. Seidmen, Appl. Phys. Lett. 92, 124107 (2008).

[12] M.E. Krug, D.C. Dunand, D.N. Seidmen, Acta Mater. 59, 1700 (2011).

[13] K.V. Chuistov, Ordering and Decomposition in Supersaturated Solid Solution, RIO IMP, Kyiv 1999.

[14] M.D. Rossell, R. Erni, A. Tolley, E. Marquis, V. Radmilovic, U. Dahmen, Microsc. Microanal. 14 , Suppl 2, 1348 (2008).

[15] V. Radmilovic, A. Tolley, E.A. Marquis, M.D. Rossell, Z. Lee, U. Dahmen, Scr. Mater. 58, 529 (2008).

[16] T.V. Zaporozhetsc, A.M. Gusak, O.N. Podolyan, Usp. Fiz. Met. 13, 1 (2012).

[17] Ja.E. Geguzin, Diffuse Zone, Nauka, Moscow 1979.

[18] K.V. Chuistov, Aging of Metal Alloys, Akademperiodika, Kyiv 1994.

[19] A.G. Khachaturian, Theory of Structure Transformations in Solids, Wiley, New York 1983. 